\title{
CARACTERIZAÇÃO MECÂNICA E MICROESTRUTURAL DO FIO MÁQUINA E ARAME 10B06 COM DIFERENTES TEORES DE BORO*
}

\section{Resumo}

Taciana Rezende Pereira ${ }^{1}$ Miguel Justino Ribeiro Barboza ${ }^{2}$ Helio Fidêncio Linhares ${ }^{3}$

Giulliane Meireles Casali Gonçalves ${ }^{4}$

O aço 10B06 é utilizado na produção de fio máquina para trefilação. Por ser produzido em aciaria elétrica, o teor de nitrogênio desse aço é elevado, o que pode causar envelhecimento por deformação, resultando em aumento de resistência e queda de ductilidade. Reduzir o teor de nitrogênio livre é uma forma de minimizar esse efeito, o que é feito pela adição de boro. O presente trabalho teve como objetivo realizar uma caracterização mecânica e microestrutural de materiais com teores de boro variando de 55 a 112ppm's. Nas propriedades mecânicas obtidas no fio máquina, foi observada uma redução do limite de resistência com o aumento do teor de boro, evidenciando o seu efeito em minimizar $\mathrm{o}$ envelhecimento. $\mathrm{Na}$ análise metalográfica, as microestruturas apresentaram-se similares para todos os testes. Nas imagens do reagente Le Pera foram identificadas três fases, austenita retida e/ou martensita, ferrita e perlita. A presença de martensita não era esperada nesse aço. O que pode ter potencializado a sua formação é a presença de boro livre, que pode causar aumento da temperabilidade. Nos próximos passos desse trabalho serão feitas outras análises para confirmar esse resultado, como microdureza, MEV-EDS e detalhamento do processo produtivo do fio máquina. .

Palavras-chave: Fio máquina baixo carbono; Laminação a quente; Boro; Trefilação.

\section{MECHANICAL AND MICROSTRUCTURAL CHARACTERIZATION OF WIRE RODS AND WIRE DRAWN STEEL 10B06 WITH DIFFERENTS BORON CONTENTS}

\section{Abstract}

The steel 10B06 is used in the production of wire rods for cold drawing. Due the production in electric arc furnaces, the nitrogen content of this steel is high, which can cause strain aging, resulting in increase of the strength and decrease of the ductility. Reduce the free nitrogen content is one way to minimize this effect, which is made by adding boron. This study aimed to carry out a mechanical and microstructural characterization of materials with boron contents ranging from 55 to $112 \mathrm{ppm}$ 's. Mechanical properties obtained in the wire rods showed a reduction in tensile strength with increasing boron content, indicating its effect on minimizing aging. In the metallographic analysis the microstructures showed to be similar for all tests. The images of the reagent Le Pera identified three phases, retained austenite and / or martensite, ferrite and pearlite. The presence of martensite was not expected in this steel. What may caused their formation is the presence of free boron, which can increase hardenability. In the next steps of this work further analysis will be done to confirm this result, such as microhardness, SEM-EDS and detailing the production of wire rod case.

Keywords: Low carbon wire rod; Hot rolling; Boron; Drawing.

1 Engenheira Metalurgista UFMG, Mestranda em Engenharia de Materiais EEL USP, Engenheira de Produto, Votorantim Siderurgia, Resende, Rio de Janeiro, Brasil.

2 Engenheiro Mecânico UNESP, Mestre em Engenharia Mecânica UNESP, Doutor em Engenharia Aeronáutica e Mecânica ITA, Professor, USP EEL, Lorena, São Paulo.

3 Especialista em Metalografia, Consultor de metalografia, Votorantim Siderurgia, Resende, Rio de Janeiro, Brasil

4 Engenheira de Produção (cursando) UNESA, Metalógrafa, Votorantim Siderurgia, Resende, Rio de Janeiro, Brasil. 


\section{INTRODUÇÃO}

O fio máquina baixo carbono produzido por aciaria elétrica tem seu uso em muitas aplicações, incluindo pregos, arames, grades, entre outros. Esses produtos são fabricados a frio por meio de deformações elevadas durante o processo de trefilação. O boro tem como principais efeitos nesses casos, aumentar a temperabilidade do aço e reduzir o efeito do envelhecimento [REIS, 2009].

Quando comparado com aços sem boro de igual temperabilidade, estes aços C-Mn$\mathrm{B}$ têm conformabilidade superior, igual ou melhor usinabilidade e menor tendência à formação de trincas de têmpera [SUSKI, 2007].

Verificou-se que adições de boro entre $0,006 \%$ e 0,020\% tornam não envelhecíveis os aços de baixo carbono capeados e semi-acalmados destinados a estampagem profunda [SOUZA, 1989].

O envelhecimento por deformação é definido como um conjunto de variações de propriedades decorrentes da interação entre átomos de soluto intersticiais e discordâncias durante ou após a deformação plástica, que implicam no aumento de resistência e na queda da ductilidade sob determinadas condições. Um dos principais elementos intersticiais é o nitrogênio. O envelhecimento é causado pelo obstáculo ao movimento das discordâncias devido ao ancoramento destas pelos átomos de nitrogênio, de pequeno raio atômico. Dessa forma, reduzir o teor de nitrogênio livre é uma forma efetiva de fazer com que as discordâncias possam se mover mais facilmente, reduzindo o efeito do envelhecimento. Uma das formas de se controlar o envelhecimento por deformação relacionado ao nitrogênio livre em aços é através da adição de elementos que possuam alta afinidade com o nitrogênio. O boro adicionado ao aço irá reagir com o nitrogênio livre e formar nitreto de boro, através da reação química: $\mathrm{B}+\mathrm{N}=\mathrm{BN}$. Esse composto, além de ajudar na diminuição da quantidade de ferrita pró-eutetóide, diminui a quantidade de nitrogênio livre, minimizando os efeitos do primeiro estágio do envelhecimento [REIS, 2009].

O nitrogênio é um elemento nocivo aos aços por causar fragilidade aos mesmos e é eliminado pela formação de nitretos com outros elementos adicionados com essa finalidade. A formação de nitretos pode causar precipitação deste composto, ocasionando o efeito de envelhecimento; a precipitação se dá de uma maneira dispersa, endurecendo o material [SOUZA, 1989].

Quando o aço contém boro em adições altas, o limite de escoamento diminui, alargando a fase plástica do material pela combinação do boro com o nitrogênio. Quando se deseja essa condição, não se deve introduzir excesso de elementos formadores de nitreto. Finalmente, o boro melhora a ductilidade por fluência de aços de baixa e alta liga [SOUZA, 1989].

O aço 10B06 é utilizado na produção de fio máquina para trefilação com diâmetro inicial de 5,50mm.

Por ser produzido em aciaria elétrica, o teor de nitrogênio é mais elevado do que os aços produzidos em alto forno ou aciaria LD (Linz-Donawitz).

Em função do teor de nitrogênio adiciona-se o boro objetivando eliminar o nitrogênio livre reduzindo o envelhecimento pela formação de BN.

O boro no aço baixo carbono modifica a rede de cementita, transformando $80 \%$ do carbono da estrutura ortogonal da cementita em CCC da ferrita, que é dútil.

A adição de boro nos aços eleva a sua ductilidade pois esses átomos segregam nos contornos dos grãos, podendo ocupar vacâncias que se formam durante o processo de trefilação e, assim, prevenir a formação e propagação de trincas no contorno do grão. 
O presente trabalho tem como objetivo estudar o efeito do boro do aço $10 \mathrm{~B} 06$ nas características dos produtos finais desse aço e na sua aplicação.

Esse estudo será feito através da realização de testes no aço 10B06 com teores variados de boro. O resultado desses testes será avaliado tanto no fio máquina quanto no arame trefilado. O trabalho será complementado com análises metalográficas e ensaios mecânicos.

\section{MATERIAIS E MÉTODOS}

Para o desenvolvimento desse trabalho foi utilizado fio máquina com diâmetro inicial de 5,50mm aço 10B06, conforme composições químicas da tabela abaixo:

\begin{tabular}{|c|c|c|c|c|c|c|}
\hline TESTE & C & $\mathbf{P}$ & $S$ & $M n$ & B & $\mathbf{N}$ \\
\hline 1 & 0,08 & 0,013 & 0,021 & 0,40 & 0,0055 & 0,0147 \\
\hline 2 & 0,09 & 0,014 & 0,012 & 0,37 & 0,0070 & 0,0142 \\
\hline 3 & 0,08 & 0,014 & 0,014 & 0,40 & 0,0089 & 0,0143 \\
\hline 4 & 0,08 & 0,016 & 0,019 & 0,41 & 0,0090 & 0,0128 \\
\hline 5 & 0,11 & 0,015 & 0,006 & 0,41 & 0,0101 & 0,0117 \\
\hline 6 & 0,09 & 0,018 & 0,011 & 0,37 & 0,0100 & 0,0152 \\
\hline 7 & 0,08 & 0,013 & 0,013 & 0,40 & 0,0112 & 0,0126 \\
\hline
\end{tabular}

Os fios máquina dos testes 2, 3, 4 e 5 foram processados em um cliente da Votorantim Siderurgia. $O$ equipamento possui 12 passes, levando a uma do arame trefilado de 1,50mm, conforme reduções de área mostradas na tabela abaixo.

Tabela 2 - Redução por passe do processo de trefilação do fio máquina.

\begin{tabular}{ccccccccccccc}
\hline Passe & $\mathbf{1}$ & $\mathbf{2}$ & $\mathbf{3}$ & $\mathbf{4}$ & $\mathbf{5}$ & $\mathbf{6}$ & $\mathbf{7}$ & $\mathbf{8}$ & $\mathbf{9}$ & $\mathbf{1 0}$ & $\mathbf{1 1}$ & $\mathbf{1 2}$ \\
Bitola (mm) & 4,70 & 4,02 & 3,48 & 3,05 & 2,70 & 2,39 & 2,14 & 1,92 & 1,72 & 1,65 & 1,57 & 1,50 \\
Redução & $12 \%$ & $27 \%$ & $25 \%$ & $23 \%$ & $22 \%$ & $22 \%$ & $20 \%$ & $20 \%$ & $20 \%$ & $8 \%$ & $12 \%$ & $6 \%$ \\
\hline
\end{tabular}

$\mathrm{Na}$ trefilação foram retiradas amostras do $4^{\circ}$ e $8^{\circ}$ passes e do produto final. A tabela abaixo representa todos os experimentos realizados, totalizando 19 amostras diferentes (composição química $\mathrm{x}$ bitola):

\begin{tabular}{|c|c|c|c|c|}
\hline TESTE & $\begin{array}{c}\text { FM } \\
5,50 \mathrm{~mm}\end{array}$ & $\begin{array}{c}\text { Arame } 4^{\circ} \text { Passe } \\
3,03 \mathrm{~mm}\end{array}$ & $\begin{array}{c}\text { Arame } 8^{\circ} \text { Passe } \\
2,02 \mathrm{~mm}\end{array}$ & $\begin{array}{c}\text { Produto } \\
\text { final } \\
1,50 \mathrm{~mm}\end{array}$ \\
\hline 1 & $X$ & & & \\
\hline 2 & $X$ & $x$ & $X$ & $x$ \\
\hline 3 & $x$ & $x$ & $x$ & $x$ \\
\hline 4 & $x$ & $x$ & $x$ & $x$ \\
\hline 5 & $x$ & $x$ & $x$ & $x$ \\
\hline 6 & $x$ & & & \\
\hline 7 & $X$ & & & \\
\hline
\end{tabular}


Foi realizada análise metalográfica em amostras de todos os experimentos utilizando os reagentes Nital 3\% (solução de ácido nítrico em álcool etílico) e Le Pera (1g de Metabissufito de sódio dissolvido em $100 \mathrm{ml}$ de água destilada $+4 \mathrm{~g}$ de ácido pícrico dissolvido em $100 \mathrm{ml}$ de álcool etílico). O reagente Nital tem como objetivo revelar os contornos de grão da ferrita, perlita, martensita e austenita bainita. Já o Le Pera tem como função principal revelar a presença de martensita e/ou austenita retida, que aparecem com coloração branca.

Foram realizados 3 ensaios de tração para cada experimento realizado, totalizando 57 ensaios.

\section{RESULTADOS E DISCUSSÃO}

\subsection{Ensaio de Tração}

Foram realizados três ensaios de tração para cada condição estudada, dos quais foram obtidos os resultados de limite de resistência e alongamento. $\mathrm{O}$ gráfico abaixo mostra a média dos três ensaios realizados.

Tabela 4 - Resultado do Limite de Resistência (LR) em MPa, Estricção e Alongamento (Al.) em \%.

\begin{tabular}{|c|c|c|c|c|c|c|c|c|}
\hline \multirow{2}{*}{ Teor B } & \multicolumn{2}{|c|}{ Fio Máquina } & \multicolumn{2}{|c|}{ 40 Passe } & \multicolumn{2}{|c|}{ 80 Passe } & \multicolumn{2}{|c|}{ Produto Final } \\
\hline & LR & Estricção & LR & $\mathrm{Al}$ & LR & Al & LR & Al \\
\hline $55 \mathrm{ppm}$ 's & 434 & 76,6 & & & & & & \\
\hline 70ppm's & 410 & 79 & 820 & 2,2 & 943 & 1,8 & 1020 & 1,5 \\
\hline 89ppm's & 407 & 77 & 823 & 2,2 & 924 & 1,7 & 1070 & 2 \\
\hline 90ppm's & 413 & 77,3 & 800 & 2,3 & 925 & 1,7 & 1018 & 2 \\
\hline 101ppm's & 416 & 80,2 & 789 & 2 & 920 & 2,2 & 1017 & 2,3 \\
\hline 109 ppm's & 403 & 77,8 & & & & & & \\
\hline 112 ppm's & 394 & 78 & & & & & & \\
\hline
\end{tabular}

Figura 1 - Gráfico com os Limites de Resistência para os diferentes teores de boro.

\section{Limite de Resisitência x PPM's Boro}

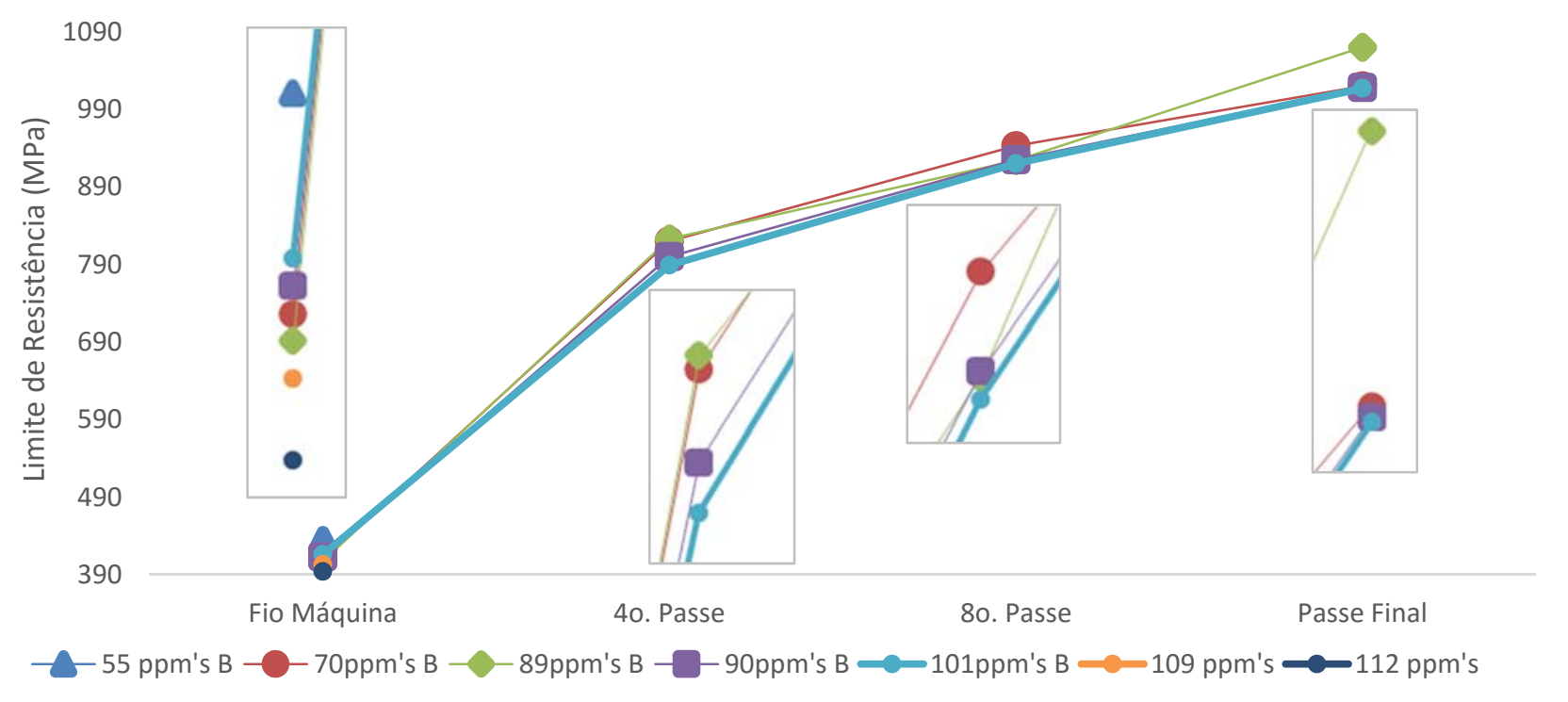


Como foi mencionado anteriormente, o nitrogênio livre funciona como uma barreira ao movimento das discordâncias, fenômeno conhecido como envelhecimento, o que implica no aumento da resistência do aço e na queda da ductilidade. O boro foi adicionado a esse aço com o objetivo de interagir com o nitrogênio livre, elemento com o qual possui grande afinidade, e formar nitreto de boro, minimizando o efeito do envelhecimento. Dessa forma, era esperado uma redução do limite de resistência com o aumento do teor de boro no aço.

De maneira geral, essa foi a tendência apresentada no gráfico. No fio máquina, observou-se uma diferença de 40MPa entre os teores de 55 e 112ppm's de boro. Essa diferença caiu para aproximadamente $30 \mathrm{MPa}$ para $04^{\circ}$ e $8^{\circ}$ passes, entre os teores de 70 e 101 ppm's de boro. Já no passe final não foi identificada diferença significativa, exceto pelo resultado observado no arame com 89ppm's de boro, que ficou 50MPa acima do encontrado nos outros experimentos.

Em função das deformações sofridas durante a redução no processo de trefilação, sabe-se que ocorre aumento da resistência. Essa elevação foi mais acentuada no fio máquina para o arame do $4^{\circ}$ passe, em função da transformação dos grãos equiaxiais do fio máquina em grãos encruados do produto trefilado, conforme observado pela inclinação da primeira reta na figura 1.

Já nas reduções posteriores ( $4^{\circ}$ passe, $8^{\circ}$ passe e passe final) a elevação da resistência ocorreu de forma menos acentuada, pois os grãos já encontravam-se deformados, conforme observado nas inclinações referentes a estes passes na figura 1.

O alongamento obtido nos arames ficou em torno de $2 \%$, o que é justificado pelo processo de trefilação realizado a frio.

\subsection{Metalografia}

Nas imagens obtidas em microscópio óptico utilizando Nital 3\%, não foi possível observar diferença significativa entre as microestruturas do produto laminado (fio máquina) dos testes realizados, ou seja, percentuais de microconstituintes e tamanho de grão similares.

Observou-se uma proporção aproximada de $90 \%$ de ferrita e $10 \%$ de perlita, o que já era esperado para um aço baixo carbono. O tamanho de grão de 9/10 ASTM.

No entanto observa-se transformação do grão equiaxial em grão encruado, consequência do processo de trefilação. Quando maior a redução (número de passes) maior será o encruamento dos grãos.

Figura 2 - Representação esquemática evidenciando deformações ocorridas durante o processo de trefilação no $4^{\circ}$ passe, $8^{\circ}$ passe e passe final, respectivamente.
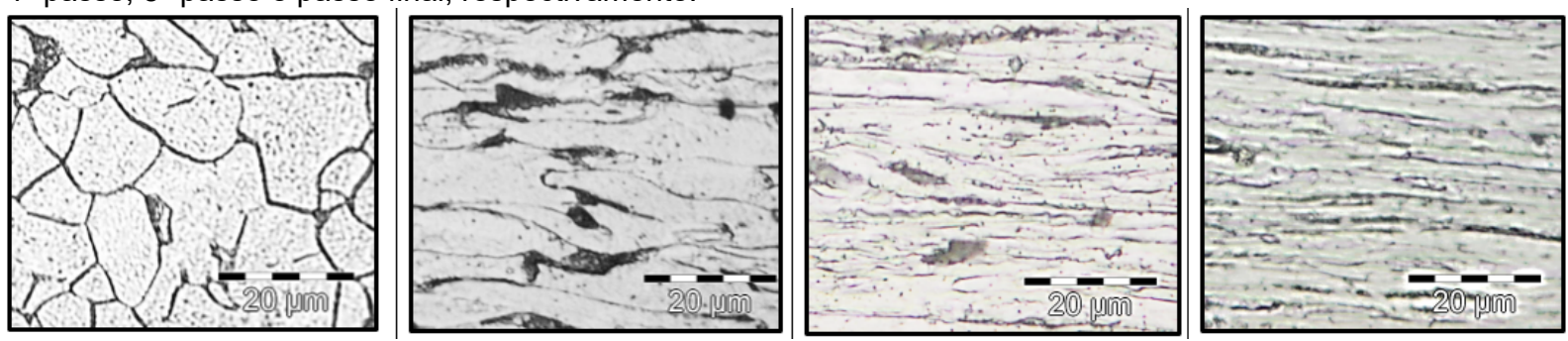

Nas imagens obtidas com ataque químico Le Pera foram identificadas três fases no material, distinguidas pela coloração, sendo branca para a austenita retida e/ou martensita, marrom para a ferrita e cinza escuro para bainita. 
Embora não seja esperada a presença de martensita nesse aço, a literatura reforça a existência de ilhas de martensita pela coloração branca.

Quando é feita uma comparação das imagens obtidas nesse trabalho, figura 3, com outros já realizados com o reagente Le Pera podemos observar similaridades. As figuras 4 e 5 mostram o mesmo tipo de coloração em trabalhos anteriores realizados por Pereira et al [4] e pela World Auto Steel [5], respectivamente. A presença da coloração branca presente nas imagens do fio máquina manteve-se nos arames $4^{\circ}$, $8^{\circ}$ passe e produto final.

Figura 3 - Microestrutura fio máquina 10B06 reagente Le Pera a) teste $1 \mathrm{com}$ ampliação de $2000 \mathrm{X}$ b) teste 2 1600x.
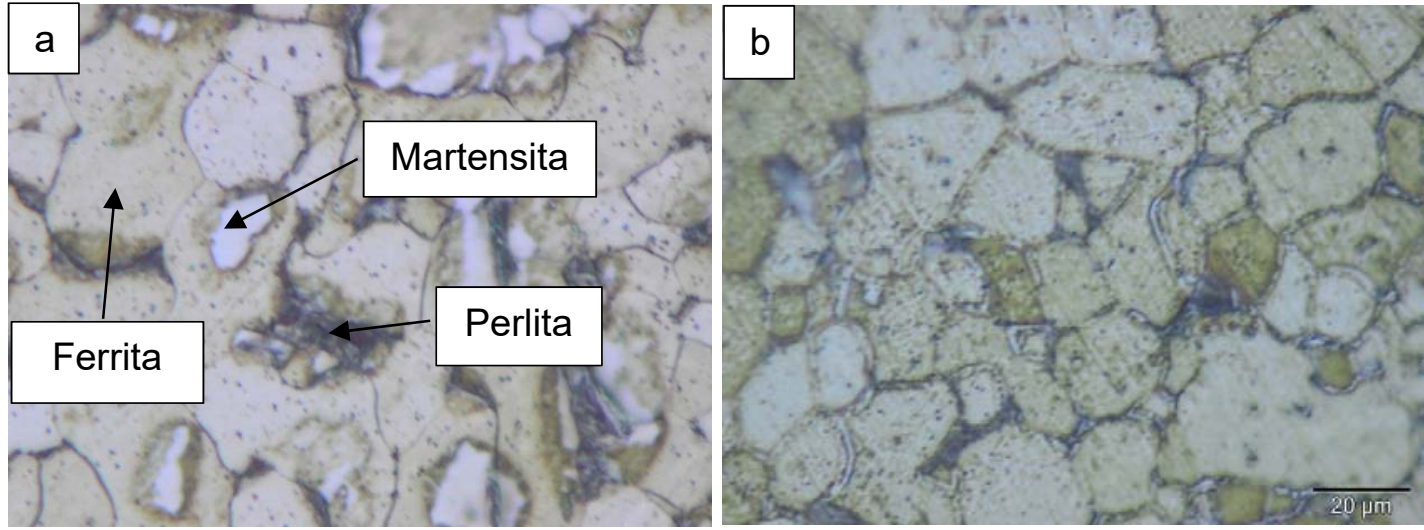

Figura 4 - Microestrutura de um aço Dual Phase com ilhas de martensita em uma matriz ferrítica.

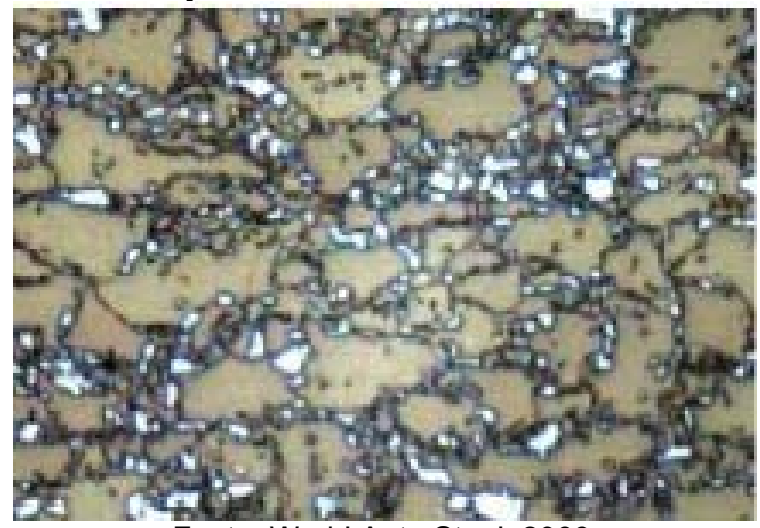

Fonte: World Auto Steel, 2009.

Figura 5 - Amostra atacada com reagente Le Pera..

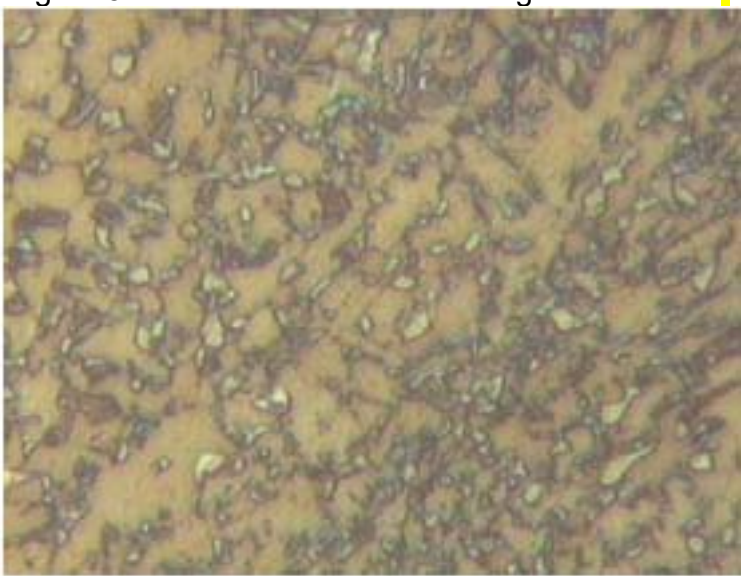

Fonte: PEREIRA, 2002 


\subsubsection{Fio Máquina:}

Figura 6 - Microestrutura fio máquina 10B06 teste 1 com ampliação de $1000 \times$ a) ataque Nital b) Le Pera.
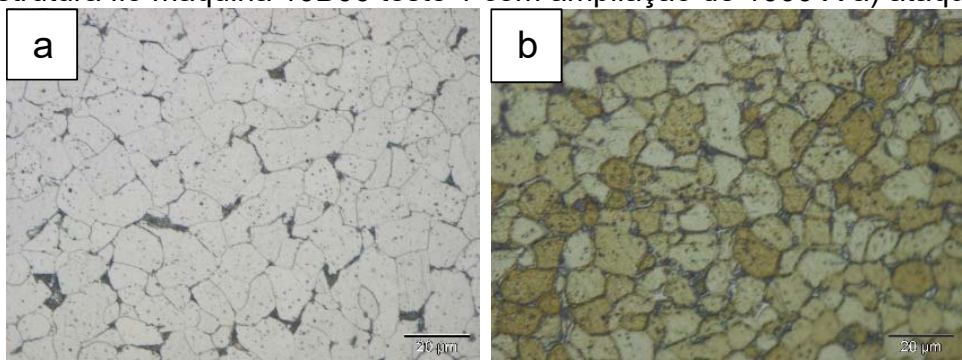

Figura 7 - Microestrutura fio máquina 10B06 com ampliação de $1000 \mathrm{X}$ a) teste 2 b) teste 3 c) teste 4.

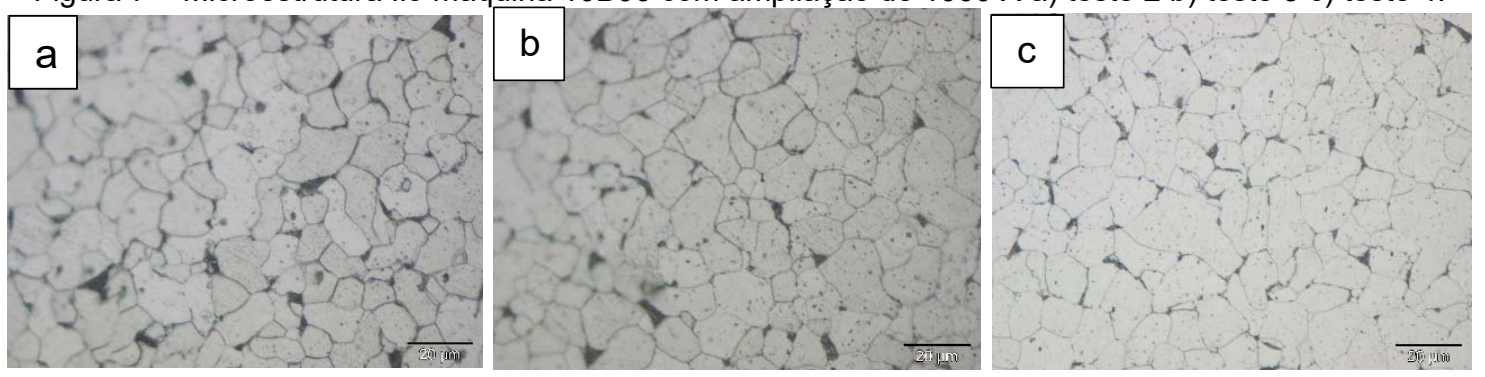

Figura 8 - Microestrutura fio máquina 10B06 com ampliação de $1000 \mathrm{X}$ a) teste $5 \mathrm{~b}$ ) teste $6 \mathrm{c}$ ) teste 7 .
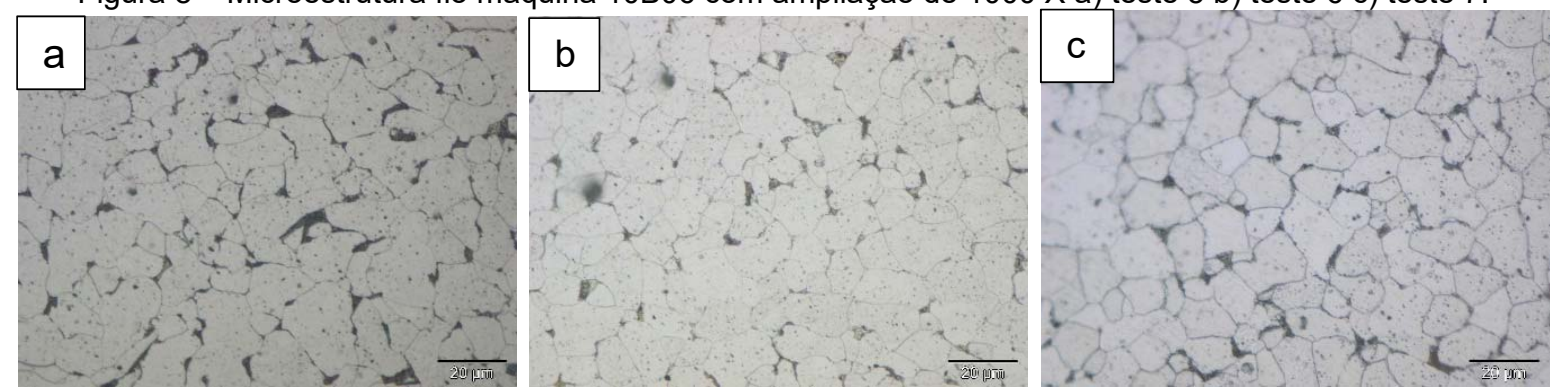

\subsection{2 $4^{\circ}$ Passe:}

Figura 9 - Microestrutura arame do $4^{\circ}$ passe teste 2 com ampliação de $1000 \mathrm{X}$ a) ataque Nital b) Le Pera.
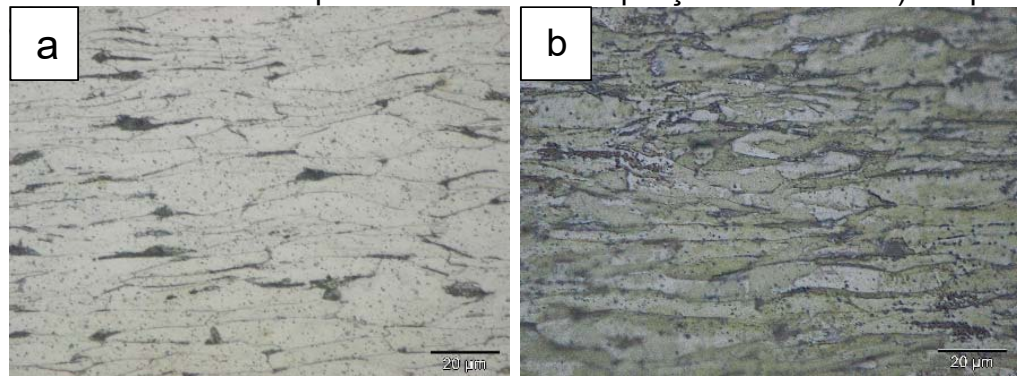
Figura 10 - Microestrutura arame do $4^{\circ}$ passe teste 3 a) ataque Nital com ampliação de $1000 \mathrm{X}$ b) Le Pera com ampliação de 1000 X c) Le Pera com ampliação de 2000 X.
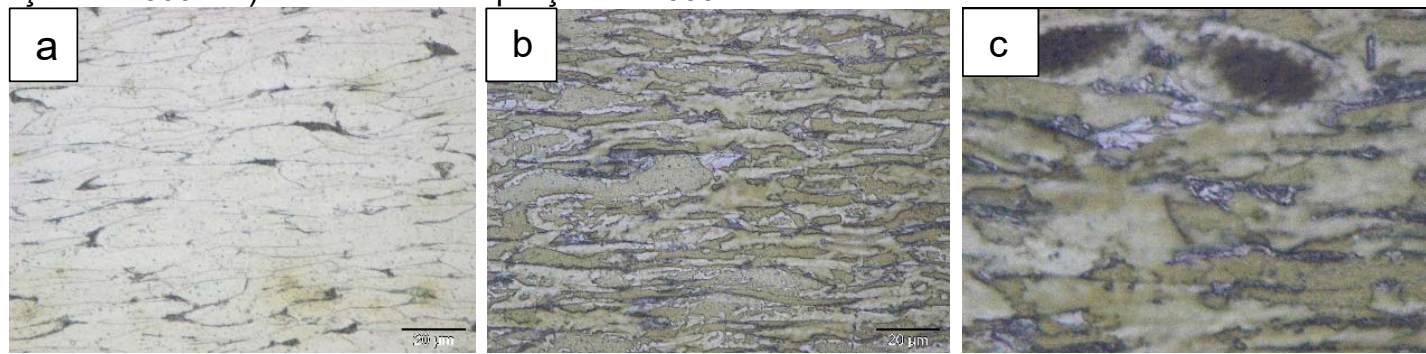

Figura 11 - Microestrutura arame do $4^{\circ}$ passe teste 4 com ampliação de $1000 \mathrm{X}$ a) ataque Nital b) Le Pera.
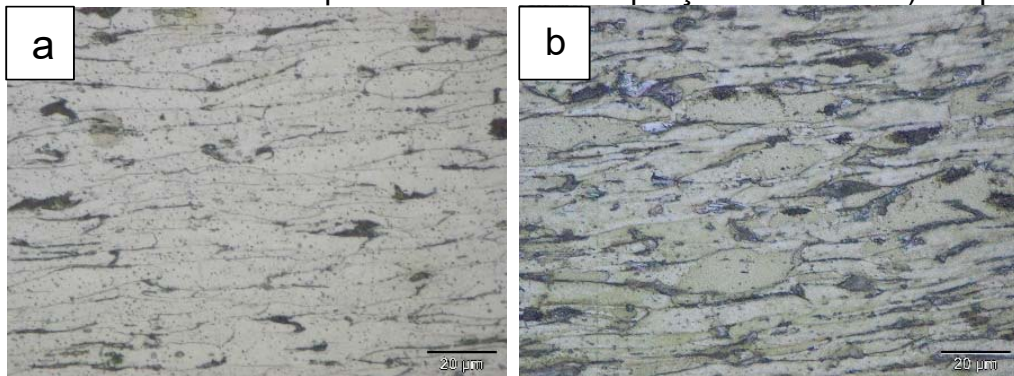

Figura 12 - Microestrutura arame do $4^{\circ}$ passe teste $5 \mathrm{com}$ ampliação de $1000 \mathrm{X}$ a) ataque Nital b) Le Pera.
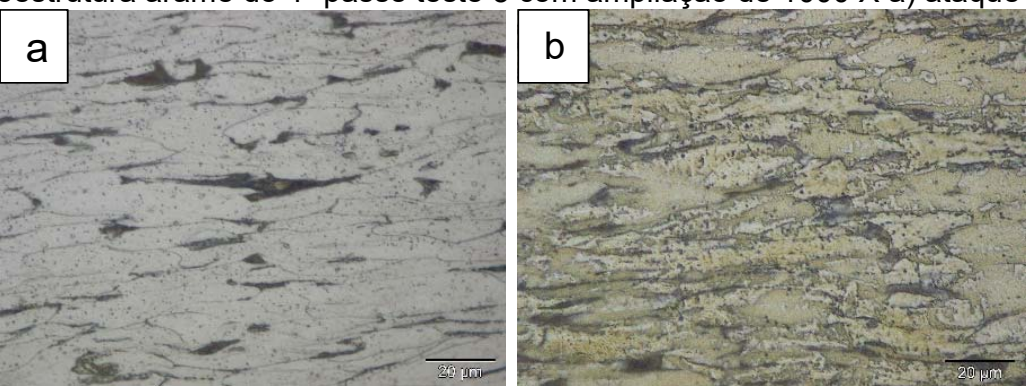

\subsection{3 $8^{\circ}$ Passe:}

Figura 13 - Microestrutura arame do $8^{\circ}$ passe teste 2 com ampliação de $1000 \mathrm{X}$ a) ataque Nital.

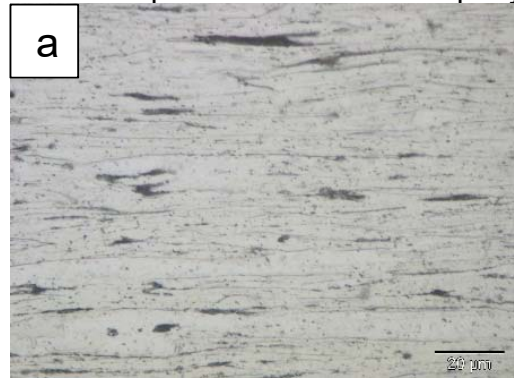

Figura 14 - Microestrutura arame do $8^{\circ}$ passe teste 3 com ampliação de $1000 \mathrm{X}$ a) ataque Nital b) Le Pera.

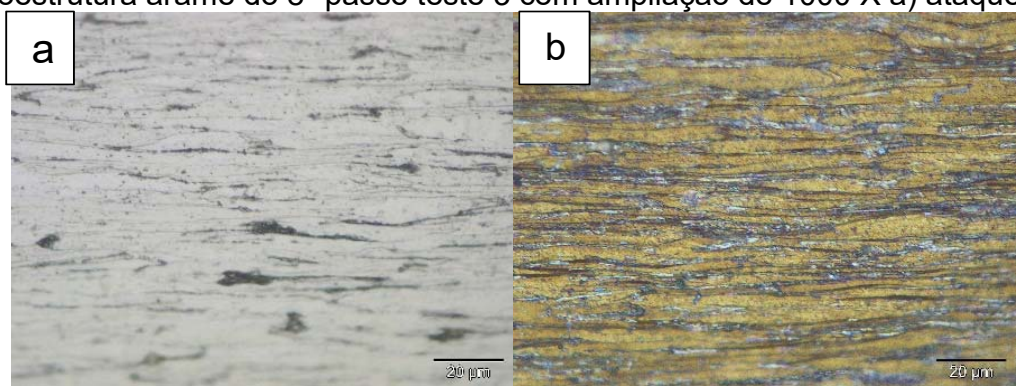


Figura 15 - Microestrutura arame do $8^{\circ}$ passe teste 4 com ampliação de $1000 \mathrm{X}$ a) ataque Nital b) Le Pera.
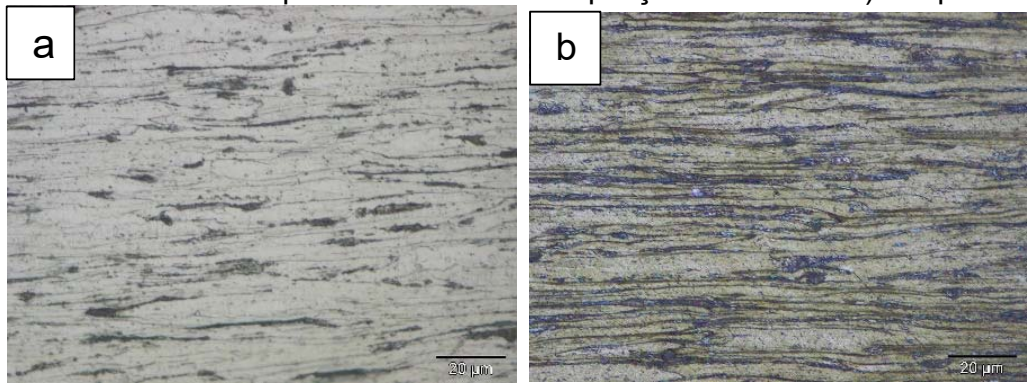

Figura 16 - Microestrutura arame do $8^{\circ}$ passe teste 5 com ampliação de $1000 \mathrm{X}$ a) ataque Nital b) Le Pera.
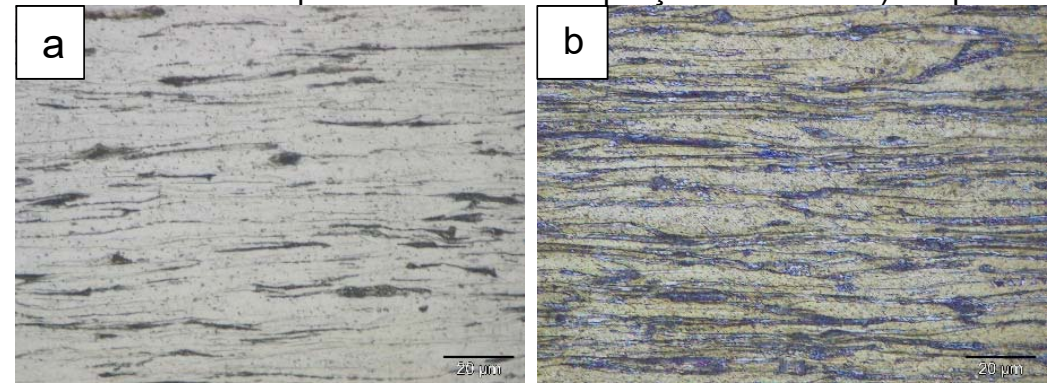

\subsubsection{Produto Final:}

Figura 17 - Microestrutura arame com ampliação de $1000 \mathrm{X}$ a) teste 2 b) teste 3.
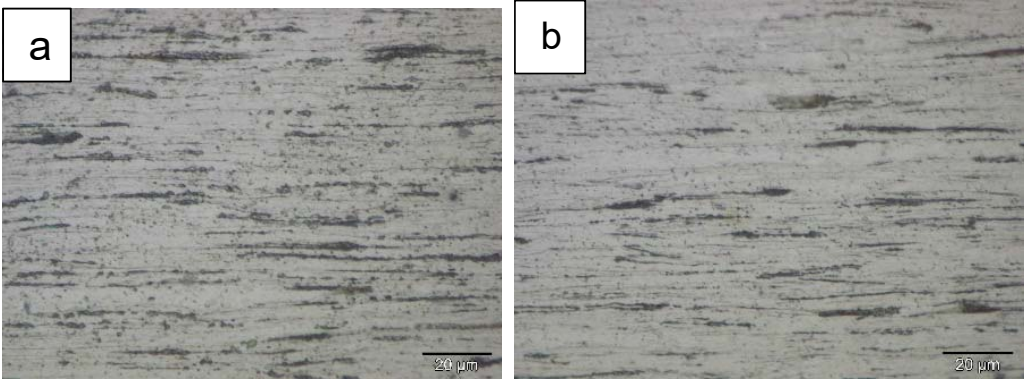

Figura 18 - Microestrutura arame com ampliação de $1000 \mathrm{X}$ a) teste 4 b) teste 5 .
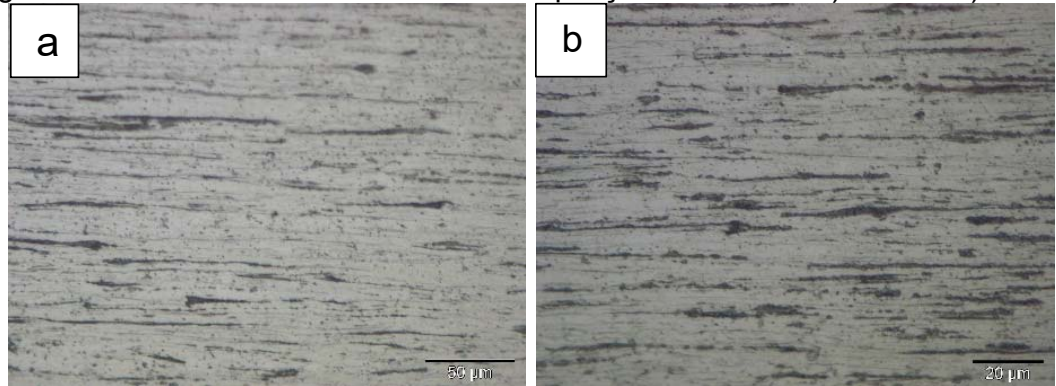

\section{CONCLUSÃO}

Foi observada uma diferença de 40MPa entre os fios máquina de menor e maior teor de boro (55 e 112ppm's). A redução do limite de resistência com o aumento do teor de boro evidencia o efeito desse elemento na redução do envelhecimento que pode ser causado pelo nitrogênio. Apesar dessa diferença, as duas condições atendem ao valor especificado para esse produto, de $343 \mathrm{MPa}$ a $424 \mathrm{MPa}$.

Já no produto final, não foi identificada diferença significativa entre o limite de resistência do arame de menor e maior teor de boro (70 e 101ppm's). Já o arame com teor intermediário de boro (89ppm's) apresentou um limite de resistência de $1070 \mathrm{MPa}$, 
$50 \mathrm{MPa}$ acima da média dos outros. Essa diferença é significativa, principalmente considerando que o valor máximo aceitável para essa aplicação é de $1080 \mathrm{MPa}$. Essa diferença pode ter sido causada por alguma alteração no processo produtivo, ou do fio máquina ou durante a trefilação, já que a composição química desse material não apresentou nenhuma outra alteração quando comparada aos outros materiais.

Foi realizada metalografia com Nital $3 \%$ em todos os experimentos, o que mostrou uma microestrutura praticamente igual para todas as composições. No fio máquina os grãos apresentaram-se equiaxiais, o que foi alterado no $4^{\circ}, 8^{\circ}$ passe e produto final, nos qual os grãos se alongaram significativamente, em função do encruamento sofrido ao longo do processo de trefilação.

As imagens obtidas com o reagente Le Pera identificaram a presença de ilhas de martensita, tanto na microestrutura do fio máquina quanto na dos arames. Esse microconstituinte não era esperado em um aço de baixo carbono. Um fato que poderia potencializar a formação dessa martensita seria a presença de boro livre no material. Parte do boro adicionado pode não ter reagido com o nitrogênio. Nessa forma, o boro aumenta a temperabilidade do material, tornando-o mais propenso à formação de martensita. Dessa forma, nos próximos passos desse trabalho devem ser feitas outras análises para confirmar a presença da martensita, como microdureza e MEV-EDS, e também análise do processo de produção do fio máquina (temperatura e velocidade de resfriamento), para tentar entender a formação desse microconstituinte.

\section{REFERÊNCIAS}

1. REIS, L. Estudo do efeito do boro e das condições de trefilação na delaminação de aços perlíticos. Belo Horizonte: Escola de Engenharia da UFMG, 2009. 83p. (Dissertação, Mestrado em Engenharia Metalúrgica).

2. SUSKI, CÁSSIO. Estudo da influência da adição de boro nos aços de baixo carbono. Revista do Parafuso, 2007.

3. SOUZA, S. A. DE. Composição Química dos Aços. $1^{\text {a }}$ Edição, Editora Edgard Blucher Ltda, São Paulo, 1989.

4. PEREIRA, M.S., GARCIA, P.E.L., HASHIMOTO, T.M, "Metalographic procedure to microstructural characterization of a multiphase steel applied to pipelines industry by optical microscopy", In:Microscopy and Microanalysis, pp.1328 - 1329, 2002.

5. WORLD AUTO STEEL. Advanced High Strength Steel (AHSS) Application Guidelines, Versão 4.1. Disponível em: <www.worldautosteel.org>. 2009.. 